\title{
Bridging the digital divide: Enhancing empowerment and social capital
}

\section{Diane Charleson}

Australian Catholic University

\begin{abstract}
In the contemporary world, the digital divide constitutes a significant inequality and thus poses a very real problem of social justice - this being particularly the case for those already burdened with disadvantage and marginalisation. In this paper, As part of its commitment to Social Justice the Australian Catholic University runs a Catalyst Clemente program. CatalystClemente provides people experiencing multiple disadvantages with university level education by means of a program that aims to break the cycle of poverty, inequity and social injustice for less-advantaged and marginalised Australians .In this paper I will explore the processes and outcomes from a unit that I taught in 2011 as part of this program. The unit was titled Introduction to Media Production, and its focus was New Media and New Media production. I will examine in particular the positive outcomes that emerged from this unit in relation to the empowerment of the individual learners that I observed during the course of the unit. This was largely a result of their introduction to, and production of, new media and the transformative role this took in helping to bridge their digital divide. On the basis of this experience I will argue therefore that the digital divide can be bridged but this requires not only access to technology by disadvantaged students but more important by an engagement with content creation. In explaining how this empowerment came about I will also examine the teaching methods and learning partnerships and styles that contributed to this.
\end{abstract}

Key words: New Media, digital divide, Clemente, empowerment, social inclusion 


\section{Introduction}

Central to the Australian Catholic University's Mission statement is its commitment to social justice through teaching and learning. A key component of this mission is the University's extensive community engagement and involvement which aims to improve long-term well-being, self esteem, social and economic inclusion in society, and to promote equality and social justice that serves the common good The Clemente program is an important instrument of this commitment. Catalyst-Clemente provides people experiencing multiple disadvantages with university level education by means of a program that aims to break the cycle of poverty, inequity and social injustice for less-advantaged and marginalised Australians. In this paper, I will explore the processes and outcomes from a unit that I taught in 2011 as part of this program. The unit was titled Introduction to Media Production, and its focus was New Media and New Media production. I will examine in particular the positive outcomes that emerged from this unit in relation to the empowerment of the individual learners that I observed during the course of the unit. This was largely a result of their introduction to, and production of, new media and the transformative role this took in helping to bridge their digital divide. On the basis of this experience, I will argue therefore that the digital divide can be bridged but this requires not only access to technology by disadvantaged students but more important by an engagement with content creation. In explaining how this empowerment came about I will also examine the teaching methods and learning partnerships and styles that contributed to this.

\section{The digital divide in contemporary society}

Due to the rapid development and distribution of digital media over the last two decades, access to this media has become crucial to being an active player in our contemporary society. In most developed countries computers and mobile phones have become indispensible to how people communicate, work and learn. (Mayo, 2009) We live in the age of the information society where access to such digital media and I would argue more importantly an ability to be able to produce effective media communication is becoming central to the way our world is operating. Increasingly, lack of access to such a technology and a reluctance or inability to 
connect with this form of communication is creating a real social and cultural divide that is perhaps as potentially significant as the lack of ability to read and write.

Much has been written about the 'digital divide' and its impact on those affected. It refers to the perceived gap between those who have access to the latest information technologies and those who do not. Research tells us that there a range of factors that contribute to this digital divide along racial, economic, ethnic, and educational lines. There is a geographical divide, where access is determined by a person' location and the availability of digital opportunities. (Norris, 2003) This aspect of the divide is less relevant to this paper as all participants in this program live in the inner city of Melbourne where such opportunities do exist. More importantly for this paper is the social divide relating to differences in access between various social groups due to barriers such as class, income, education, gender and race The general trend in both developed and developing countries is that the wealthier classes have a greater access to cutting edge technology where access for the poorer classes is more through a trickledown effect (Norris, 2003). This is largely due to the start-up expenses of computers, smart phones and also in Australia the monthly bills associated with connection fees. Where statistics tell us that the digital divide is narrowing as more and more people have access to cheaper personal computers and mobile phones, there is still a divide existing in low income groups where even these cheaper costs are out of reach. Education is also another major factor in this divide. Most of the digitally excluded are more likely to be less educated with less well paid jobs and education and income appear to be among the leading elements driving the digital divide today. Since these factors vary along racial and ethnic lines, minorities will continue to face a greater digital divide as we move into the next century (Holloway, 1987) Most of the research on this issue has contended that those who have lower usage of this technology are already disadvantaged (Foley, 2001). More importantly, there remain concerns that those already disadvantaged risk exacerbating their position through continued lack of usage of technology.

However some researchers believe that this definition of the digital divide is too narrow and that the issue is not simply one of access to technology and that furthermore it is not access to on-line that closes the divide (Servon, 2002). Servon (2002) argues that while physical access to computers and the internet is certainly a key factor in defining the digital divide, there are other factors that need to be 
considered such as literacy, technological literacy, content production, use of language and availability of a network. Technological literacy is mainly about the ability of the individual to use these digital technologies effectively. It is imperative that users have ownership of the technology and confidence with it so that they can become empowered producers rather than tentative passive users. In order to be effective users, I would argue that it is important to be up to date with software and hardware and also to be critical and reflective about the issues surrounding the impact of New Media on society. I would also suggest that familiarity with a range of New Media /internet content style and form, and an appreciation of audience and purpose is also critical as an empowering tool when beginning to create such content. This position was central to my approach in teaching this unit.

Ownership and access do not always equate to people using the technology as many with access are not necessarily skilled users or are unable to access material effectively. It is important that users develop adaptive literary user skills that will help them cope with new technologies and more importantly to use them effectively for the communication that they desire. There are also further barriers to disadvantaged and marginalised users when engaging with the internet. This is due to the nature of the content available on the internet, much of which has been produced and dominated by the more technologically savvy and displays a lack of participation by certain groups in the production of online content. Servon (2002) argues that "when disadvantaged groups log on they often find that there is no content there... information that is directly related to their lives ... does not exist" ( $p$. 9). In addition, Fiddler (1994) argues that often due to the lack of skills "computers ... are still used by most people as little more than electric typewriters" (p. 32). By introducing my students to the means of production relevant to working on the internet, coupled with a critical lens on already available content and a theoretical understanding of issues related to the impact of New Media, they were able to not only "feel" empowered but to also become effective internet users and producers.

Access to digital technology and I would argue more importantly being part of an effective network of content production on the internet empowers the individual. Empowerment has been defined as "the process of gaining mastery over one's self and one's environment in order to fulfil human needs" (Hartsock, 1985, p. 83) with a particular focus on people's ability to transform their lives and to motivate others. A 
process of reflection and action can help marginalized groups become more aware of their condition and they can then take steps to change their reality (Freire, 1972).

"Such empowerment can expand people's ability to make more strategic life choices and provide them with the ability and skill set to lead more fulfilling lives" (Sen, 1999, p. 18).

Empowerment can be achieved through a process of building self esteem that can come from skills attainment and learning, increasing a sense of worth and in so doing helping to enhance social capital Bourdieu (1990). It is a term that describes the different ways in which members of different communities can interact effectively. This can vary from chatting with neighbours or engaging in recreational activities, to participating in environmental organizations and political parties. It also allows for the acquisition of new sources of information and support, thus bridging social capital is considered important for social development. Access to the internet and the development of content production skills opens up a plethora of new forms of interaction by enhancing individual's social capital. It provides opportunities to communicate with a worldwide audience and most importantly provides a voice in a public arena for the previously voiceless and disadvantaged in a way that has not been available to this extent before.

\section{The learning and teaching experience}

\section{Background}

The Melbourne campus of ACU offers a Clemente program each year. It consists of a Certificate of Liberal Studies offered to selected disadvantaged and marginalised people who apply and who demonstrate a willingness to participate and learn. The students can take one unit per semester. These units are taught by ACU academic staff from the School of Arts and Sciences and each unit is selected from existing undergraduate degrees. On completion of four units students can graduate with the Certificate and are then eligible to enter a university undergraduate degree.

In 2011, I was asked to teach a unit and opted for Introduction to Media Production. This is a compulsory first year unit in the Bachelor of Media Production at ACU. I am the co-ordinator of this degree and come from a long background in media production. The unit was taught as a two hour face to face class supported by staff from Clemente. Classes run over a twelve week semester. These classes were 
reinforced by a two hour session later in the week where each student is paired with a learning partner, a partnership that provides the scaffolding and support which students need for developing skills and confidence for successful completion of the unit. These learning partners are volunteers and are trained to support the student with their studies. As well, the students have regular counselling meetings with trained Clemente staff who are available to students throughout the semester.

\section{The students}

The students who participated in this unit were all mature age, ranging from late twenties to 60 years of age and were also of mixed gender and ethnicity. They came from a variety of disadvantaged backgrounds all having experienced a major dislocation from the education process through issues such as major trauma, family dysfunction, substance abuse, or personality and psychological issues. All were marginalised in some way from the mainstream and had entered the Clemente program as a means of re-entering the world. They had a clear desire to learn and they all brought with them a good deal of experience and knowledge in a range of areas. Their expectations were varied as was their experience of the learning process. All had very competing interests outside of the program, often of greater importance to them than their classroom learning but they all remained in the unit for the full duration and generally were committed, motivated and engaged with the learning process.

\section{The unit}

In devising the unit, Introduction to Media Production, I divided it into three parts, distinct yet interrelated, each of four weeks duration. The first four weeks were devoted to writing and producing a blog. The second third was designed around exploration and research into issues emanating from New Media. Here students watched films, had class discussions, collected references, culminating in an oral presentation focused on an issue of the student's choice. The last third was devoted to introducing students to narrative short film making and developing more sophisticated media skills.

For the purposes of this paper, I will concentrate on the first four weeks, which not only introduced students to New Media but also made them into producers and users of the technology. I started with this practical application first so as to empower use and to provide a real world understanding and ownership of New Media. I 
intentionally planned these activities in order that technology use and information literacy would become part of the students' repertoire and thus contribute to their empowerment through doing. Burke (2008) suggests that approaches to lifelong learning need to take into account many complex learning approaches to engage students such as those in the Clemente program. Learning should be designed with critical engagements that draw on life experiences which are shared as well as individual. It was these objectives that I fore fronted in my design of the Unit.

\section{Producing content}

From Week 1, students were introduced to the genre of the blog, shown examples from the web and discussed form and content. I directed them in particular to a popular Blog site www.tumblr.com as it is popular with a range of bloggers, is free to access and easy to use. Students were asked to create their own blog site on this platform and shown how to do this. The application of this was carried out in their Learning Partner sessions. In terms of content production they were asked to produce a profile piece. This was done by pairing off with a fellow participant, conducting an in-depth interview with them and then writing this up after researching profile writing styles that they could model. This written entry was to be posted to their blog page. They were then shown how to use a small digital HD flip camera with emphasis on good filming practice. They were asked to supplement their oral interviews with a video interview of their subject which would complement what information they already had and offer an added dimension to their profile. This they recorded themselves in class and then were asked to upload this to their blog page. Similarly they were invited to take or choose a photograph that represented an aspect of their subject and also upload this to the blog. In effect they were becoming creators of content on the internet and entering a whole new world of possibilities for communication and voice. They were partaking in the "living humanities," as Shorris (2000) advocated, where the focus was on the process of reflection, communication, and self-development.

Although this exercise may seem straightforward enough to practising internet users, one must keep in mind the skill set of the students who were faced with the task. While some students were completely new to the Clemente program others had already participated in Clemente units before so were used to studying, however none were familiar with this type of practical/action approach to learning. At the first 
class, the students were tentative, interested but overall extremely anxious. The anxiety that they felt was I believe based on fear of the unknown and fear of failure coupled with a lack of belief in their own abilities. It was possible that I could have encountered a fight or flight response. Often when adult learners are faced with a request to engage in some learning activity that is outside their comfort zone, there can be individual or group resistance, for example, a response such as 'we don't want to do this' or, 'Why should we do this?'. In other cases, students might respond by taking flight and dropping out. Thus I was confronted with the anxiety of the students but not their negativity. Fortunately there was no flight and only a small amount of fight but I encouraged perseverance through my enthusiasm and reassurance and by introducing participation early.

Most of the students had little or no experience with the internet as content providers, with few even having access to the internet at home. As part of the Clemente program students are given student numbers and library cards and have immediate access to computers and the internet which they can access at any time in the library. A couple of students had their own computer at home but others' only access was through community libraries. Most of the students had heard of blogging but had no experience with it. Also, the majority had never accessed a blog site, being unaware of what existed. The simple act of introducing them to the blog site and facilitating navigation skills opened up a wide world of communication for them and helped to alleviate anxiety by presenting opportunities and the excitement of discovery. Also, most participants did have basic computer skills which had been mainly used to complete essay assignments with some limited internet surfing and email contact.

Pivotal to the success of this unit was the role of the Learning Partner sessions. Having been introduced to concepts in class they were then able to put them into operation with the guidance of a mentor. At this point, I would like to add that the many of the Learning Partners had also never created or used a blog page and were themselves tentative, feeling more comfortable with helping students with the more traditional study skills. However, they prepared to learn alongside and with the students and they too felt excited about this entrée into New Media. This aspect was perhaps a key in the success of the unit, as instead of the students being taught by experts they were learning with them or sometimes in advance of them. This created multiple roles for the mentors and enabled collaboration, with shared 
workspaces allowing the students and partners to share their knowledge and ideas by working on projects together (Rogers, 2010).

Embracing the blog technology and becoming familiar with the interface was the most challenging part of this exercise and students varied in the speed with which this occurred. In order to avoid anxiety turning into a refusal to continue, I structured my classes with them to minimise the emphasis on the technology, concentrating instead on content creation. The focus was on the students devising questions for their profiles, workshopping interview techniques and conducting the interviews with their peers with a topic that allowed them full ownership. This exercise was not without its difficulties as it necessitated a relationship of trust and was somewhat threatening as I encouraged them to gain a real insight into their interviewee. Although they were all guided to navigate what was appropriate some were sceptical at first being reluctant to divulge too much.

We then concentrated on the literary skills of writing up the profile, modelled on a range of media examples both on line and in traditional media. This was then posted to their blogs. I must add that at no time were the students under any obligation to publish these blogs and they never proceeded without full approval of their peers who had full editorial rights. Lillis (2003) argues that students are often expected in formal educational institutions to take part in a very particular kind of literacy practice particularly the academic essay writing genre. Non traditional students often feel unfamiliar and intimidated by this academic style of writing which can often reinforce a sense of exclusion where students can feel "not good enough" or alienated from the mainstream process (Burke, 2008). The essay privileges "the discursive routines of particular social groups whilst dismissing those of people who, culturally and communally, have access to and engage in a range of other practices" (Lillis, 2003, p. 39). By allowing my students to write in a narrative voice based on material that they were familiar with and modelling on accessible best practice examples enabled them to have confidence to write and excel. The alternative vehicle of the profile blog offered, in a higher education setting, provided a greater sense of inclusion and the possibility of success. In turn this helped to relieve any anxiety in the encounter with the technology. Once students were successful in uploading to their blog sites, the amount of pride and excitement was truly evident. Now not only had students become familiar with terms such as blogging, downloading, up-loading, embedding, posting and publishing, they now had actually 
created a site and performed all of these tasks in so doing. After this initial stage, many students were excited by the possibilities presented by the blogging sites they encountered in their research. Some started an alternative site and used it to publish and showcase their art work, others to publish opinions while others now felt that they could converse on a more equal footing with their children on technological issues.

This initial written posting experience was heightened by the inclusion of video. The students learnt to use small cameras professionally with care to framing, lighting and audio as well as content. They shot their interviews during class time, and watched them back in class on the big screen. Moreover they were required to save these clips onto USB sticks, which familiarised them with this form of downloading and transferring material and by engaging with this process they thereby became more sophisticated users. They then had to upload this video to their websites with their learning partners. This aspect did have some problems due to transferring the footage, some bad directions on my part and glitches in the blog site. Although these problems occurred, and students could not be successful on first try, they all persevered with the difficulty without giving up. It is unlikely they would have shown this degree of perseverance at the start of the unit. They were prepared to deal with the technology and have it work for them. This shows the extent to which they had taken ownership of their product and their own learning.

\section{Outcomes}

The feedback I received from the students was extremely positive. This I believe was mainly due to the rise in self esteem and empowerment that they felt and perceived in having completed a task that had initially appeared so daunting to them. They realised that they were now part of the internet community, not only as observers or tentative users, but as insiders, able to interact with, and create content for, a platform of communication that they believed they has previously been excluded from. Prior to this experience, they perceived that such participation belonged to others, computer savvy folk, the educated and the elite or young people.

This mastering of New Media had at least a twofold impact on these students. Firstly, as they were in the mature age category and thus peripheral users of technology at best, they had now bridged the generational divide and secondly, as being a part of the community of the disadvantaged and marginalised, they had 
gained access to technology and had become empowered users, in the process helping to close the social divide.

Many factors were critical to this success. Firstly, it was a result of the students themselves who were very motivated and keen to learn and were prepared to be open and not daunted by any obstacles. Secondly, this success was facilitated by the teaching style I adopted. I concentrated on creating a warm environment with a strong sense of identification between myself and the students. The group atmosphere was welcoming, affirming and encouraging to the learner and not dismissive or excluding (Rogers, 2010). I structured all classes as workshops, and all of the class content was oriented to them as producers and members of the media community. Rather than a series of long lectures where students were asked to bank information, everything was student-centred and action-oriented, always mixing theory with practice. I believe that as these disadvantaged adult students, were coming to terms with such a daunting exercise as blogging for the first time, they needed to have first a practical experience of learning. Had they been overwhelmed with theory and too much talk initially this may have inhibited their willingness to tackle the tasks I set. This example of experiential learning was clearly an empowering process exemplifying that knowledge is often best acquired through active participation (McLoughlin, 1999).

Also I always had an unwavering belief that they could master the technology and be successful in using it. Being new to working in a program such as Clemente I was somewhat naive in my expectations but I believe that this naivety helped in facilitating their success. I was perceived by the students as the teacher who was most importantly a specialist in the subject and one they felt confident in as the class leader. They also allowed me to be an agent of change while also being a member of the group. I was the critical audience, the person before whom they were prepared to present their newly acquired learning and accept evaluation and reinforcement. Experiencing immediate results was also very rewarding and empowering for the students. I was always very enthusiastic, as this is my personal area of passion and such enthusiasm inspired the students in their learning. As Rogers (2010) stresses successful learning is a combination of the commitment to the learning task of both teacher and students. At the conclusion of the Unit I made a video (Charleson, 2011) of the students and their responses to what they had learnt. This is some of what they had to say about their learning experience: 
"I have learnt a great deal of knowledge and knowledge is power. I have a lot more confidence. Its special, it makes me feel great. I look forward to coming to every class."

"I've learnt skills that I feel I never had any idea they existed before."

"...learning new things, but the way it teaches, like, it's not stressful, at your own pace. You can learn new things without a lot on yourself...a pretty comfortable environment to work in."

"It's given me another limb, another part of me that I didn't have before and opened doors that weren't there before."

Since this Unit was completed one of the students, a 53 year old, who has never had formal tertiary education and disrupted secondary education, has successfully been accepted into the main stream ACU bachelor of Media Production degree. He applied through the mature age entry pathway provided by VTAC. At the beginning of my unit he was sceptical indeed about Media studies and the media in general, but now as he said "you have opened my mind's eye" and sees a future for himself in media production. "Six months ago I couldn't even put on computer on and I was very critical of media in general and now there is a whole new avenue that New Media has opened up for me and the general people and I am attracted to this" (Charleson, 2011). He has plans for using these skills in developing a business and empowering his community. Others have gone on to create blogs of their own and fully embrace the net and its opportunities.

\section{Concluding comments}

In the contemporary world, the digital divide constitutes a significant inequality and thus poses a very real problem of social justice - this being particularly the case for those already burdened with disadvantage and marginalisation. The course of study I organised as part of the Clemente program was an attempt to address this situation and whilst small-scale and local in its scope nonetheless had a clear positive impact for the participants. The key feature to the success of this venture was the teaching and learning strategy that was used. This involved a student-centred activity-based approach deliberately chosen as the means of developing the knowledge, skills and confidence of the students. Any other approach would have reduced the students to 
passive spectators in the face of the teacher who "knows all". In other words, a transmittal approach would not have worked to achieve the goal of empowerment. The students also "knowers" were able to handle the technology with confidence by producing their own media content. Related to this was the demystification of the technology and of how to work in the digital world. By trying this for themselves using the technology and becoming participants in the digital world - they enhanced their knowledge and skills, including their relational skills - and perhaps most important of all, their self-confidence.

I believe this experience will enable these students to feel empowered to tackle even more challenging technological ventures that they may well carry over to their further studies and to their social interactions. By well and truly bridging the digital divide, becoming empowered and developing social capital, by marginally lessening social inequality, a limited but significant contribution has been made to the cause of social justice. As Shorris (2000) argues democracy is enhanced by inclusion, and "the chief reward of the public life is inclusion in the circle of legitimate power" (Shorris, 2000, p. 73).

\section{References}

Bell, D. (2004). Post industrial society. In E. Webster et al. (Eds.), The information society reader. London: Routledge.

Bourdieu, P., \& Passeron, J. C. (1990). Reproduction in education, society and culture $\left(2^{\text {nd }}\right.$ ed. $)$. Thousand Oaks: Sage Publications.

Burke, P. J. (2008). Writing, power and voice: Access to and participation in higher education. Changing English: Studies in Culture and Education, 15(2), 199210.

Charleson, D. (2011). Clemente Celebration Video: Video recording.

Crook, C. (1995). On resourcing a concern for collaboration within peer interactions. Cognition and Instruction, 13, 541-547.

Fiddler, R. (1994). Newspapers in the electronic age. In E. Williams \& J. V. Pavlik (Eds.), The people's right to know: media, democracy and the information highway. London and New Jersey: Lawrence Erlbaum Associates.

Foley, G. (2001). Power, politics and the internet. Retrieved from www.koorwb.org/foley/essay

Friere, P. (1972). 'Pedagogy of the oppressed'. London: Penguin Books.

Garton, L., Haythornthwaite, C., \& Wellmann, B. (1999). Studying on-line networks. In S. Jones (Ed.), Doing internet research. Thousand Oaks, CA, and London: Sage.

Hartsock, N. (1985). Money, sex and power: Toward a feminist historical materialism. Boston: Northeastern University Press. 
Holloway, D. (1987). Developing communication skills: Learning style and the educationally disadvantaged student. Communication Research Reports, 4, 38-46.

Lillis, T. (2003). Student writing as 'academic literacies': Drawing on Bakhtin to move from critique to design. Language and Education, 17(3), 192-207.

Mäkinen, M. (2004). Digital empowerment as inclusion by enabling people to become subjects of the information society - assessments of some ICT based community communication projects. Paper presented at the Conference on Politics and Information Systems, Technologies and Applications (PISTA), Orlando, USA. Retrieved from http://www.uta.fi/ tlmama/PISTAmakinen.pdf.

Mayo, L. (2009). The digital divide: Scarcity, inequality and conflict. In G. Creeber \& M. Royston (Eds.), Digital cultures: Understanding new media (pp. 122139). Berkshire, England: Open University Press.

McLoughlin, C. (1999). Culturally responsive technology use: Developing an online community of learners. British Journal of Educational Technology, 30, 231245.

McLoughlin, C. (2000). Cultural maintenance, ownership, and multiple perspectives: Features of web-based delivery to promote equity. Journal of Educational Media, 25(3), 229-241.

Norris, P. (2003, March). Social capital and ICTs: Widening or reinforcing social networks? Presented at the International Forum on Social Capital for Economic Revival held by the Economic and Social Research Institute, Cabinet Office, Japan in Tokyo.

Rogers, A., \& Harrocks, N. (2010). Teaching adults (4 ${ }^{\text {th }}$ ed.). Berkshire, GBR: Open University Press, 2010.

Sen, A. (1999). Development as freedom. New York: Knopf Press.

Servon, L. (2002). Redefining the digital divide: Technology, community and public policy. Maiden, MA: Black.

Shorris, E. (2000). Riches for the poor: The Clemente course in the humanities. New York: Norton. Retrieved from http:www.acu.edu.au

\section{Biographical Notes}

Dr Diane Charleson is a Senior Lecturer and the Coordinator of the Bachelor of Media Communication. She has had extensive experience as a writer and director of Film and Television. She has taught extensively in the area of Media mainly at RMIT University. She is still a practising filmmaker with interests in Video Installation and documentary. She is an active researcher with interests in practice based research on the themes of memory, identity, time and place. 